\title{
Coulisses
}

Revue de théâtre

\section{Besançon Ville Ouverte aux Jeunes 1990 « Le Festival des Idées »}

Bilan et perspectives

\section{Rédaction}

\section{OpenEdition \\ Journals}

Édition électronique

URL : http://journals.openedition.org/coulisses/1579

DOI : 10.4000/coulisses. 1579

ISSN : 2546-9460

\section{Éditeur}

Presses universitaires de Franche-Comté

\section{Édition imprimée}

Date de publication : 1 novembre 1990

Pagination : np

ISSN : 1150-594X

\section{Référence électronique}

Rédaction, «Besançon Ville Ouverte aux Jeunes 1990 « Le Festival des Idées » », Coulisses [En ligne],

2 | Automne 1990, mis en ligne le 04 juillet 2017, consulté le 22 octobre 2019. URL : http://

journals.openedition.org/coulisses/1579; DOI : 10.4000/coulisses.1579

Ce document a été généré automatiquement le 22 octobre 2019.

Coulisses 


\section{Besançon Ville Ouverte aux Jeunes 1990 «Le Festival des Idées »}

Bilan et perspectives

\section{Rédaction}

\section{Positif}

1 «C'est une bonne chose, cela donne une chance aux jeunes... »

2 "C'est une bonne initiative qui permet à des troupes diverses de s'exprimer en même temps; elle permet à chacun de taire des essais dans des conditions matérielles convenables... »

3 « Elle fait place à des spectacles qui n’auraient pas été créés sans elle... »

\section{Contradiction}

4 «La manifestation assure davantage la promotion de la ville que celle des jeunes. Le public est mal informé, l'affiche de BVOJ 90 est restée un mystère pour les noninitiés... »

5 «La date n'est pas bien choisie car les lycéens passent le bac et les étudiants leurs examens...»

\section{Proposition}

6 «Il faudrait trois rendez-vous annuels importants, et travailler en continu. Il y a des besoins d'approfondissement et de sélection. Il serait intéressant d'inviter des intervenants de l'extérieur...» 


\section{Réunion-bilan. Les points sensibles}

7 La publicité : Le rapport entre publicité collective et particulière n'a pas toujours été bien compris. Les groupes les moins structurés et les moins connus ne bénéficient d'aucune aide complémentaire.

8 Le public : Environ 12000 personnes, reste celui des fidèles de chaque groupe sans s'intéresser à ce qui se passe ailleurs. Quelle solution? Une manifestation d'ouverture et de clôture avec la participation de chaque groupe.

$9 \quad$ Les lieux : Ne serait-il pas judicieux que la manifestation se déroule sur d'autres lieux que ceux du centre-ville, voire sur des lieux méconnus, comme l'a fait le Théatre universitaire au terrain de sports de la Bouloie?

10 Les photographes : L'Atelier photo a pris en charge de photographier les spectacles. Souvent sans consultation préalable des responsables. C'est dommage. Certains clichés sont décevants. L'exposition à la salle Proudhon n'était pas assez connue.

11 Le calendrier : Quelles qu'en soient les raisons, quel dommage qu'il n'y ait eu aucun spectacle le dimanche!

12 Les professionnels : Quel est leur rôle dans la manifestation? Quel peut-il être ?

13 Les autres arts : À l'unanimité que se développe la participation de tous les arts et plus particulièrement celle des arts plastiques...

\section{En résumé : Que BVOJ persiste et se développe}

Deux tendances semblent se dégager: l'une reprend la formule actuelle de concentration, de festival d'amateurs d'art, quelle qu'en soit la nature, et nécessite approfondissement et affinement de ce qui se fait actuellement; l'autre propose une manifestation étalée dans le temps et par thème, plus formatrice, et reste à inventer.

Les deux démarches pourraient être complémentaires. Les rendez-vous de l'année servant en quelque sorte de tremplin à la rencontre annuelle. La question de la sélection ne se poserait plus dans les mêmes termes.

En l'ouvrant largement aux jeunes des villes jumelées avec Besançon, elle pourrait devenir ce carrefour européen de la jeunesse créatrice, non par profession, mais par plaisir. 